\title{
Capacitance-based microfluidic device for early ammonia detection in river water
}

\author{
Muhammad Muhaimin bin Ramli ${ }^{1}$, Mohd Ridzuan bin Ahmad ${ }^{2}$ \\ ${ }^{1,2}$ School of Electrical Engineering, Universiti Teknologi Malaysia, Malaysia
}

\begin{tabular}{l}
\hline \hline Article Info \\
\hline Article history: \\
Received Feb 9, 2020 \\
Revised Apr 7, 2020 \\
Accepted Apr 21, 2020 \\
\hline
\end{tabular}

\section{Keywords:}

Ammonia

Capacitance

Microfluidic

River

\begin{abstract}
This paper proposes a design of a microfluidic device for early detection of ammonia in river water based on capacitance measurement. A microfluidic device is designed and simulated to measure the content of ammonia in river water by using the COMSOL finite element analysis (FEA) software. This paper describes the system in detail from the conceptual idea to the hardware implementation. The microfluidic device works by inserting the sample of water into the device to be tested. A pair of electrodes is connected to the electrical circuit and the value of the capacitance of the water sample is measured. The tested samples are normal river water and contaminated river water which have ammonia in it. Several investigations have been done via the simulation, i.e. the size of the electrode, the difference in water flow gap, the distance between the electrode, speed of the water and the capacitance of the water. The results show that the proposed microfluidic design is capable to detect ammonia inside river water under 2 ppm concentration.
\end{abstract}

Copyright $\odot 2020$ Institute of Advanced Engineering and Science. All rights reserved.

\section{Corresponding Author:}

Mohd Ridzuan bin Ahmad,

Division of Control and Mechatronic Engineering,

School of Electrical Engineering,

Faculty of Engineering, Universiti Teknologi Malaysia,

81310 Skudai, Johor, Malaysia.

Email: mdridzuan@utm.my

\section{INTRODUCTION}

Ammonia is a nutrient that contains nitrogen and hydrogen. Its chemical formula is $\mathrm{NH} 3$ in the un-ionized state and $\mathrm{NH} 4+$ in the ionized form. Ammonia is the preferred nitrogen-containing nutrient for plant growth. Ammonia can be converted to nitrite (NO2) and nitrate (NO3) by bacteria, and then used by plants. Nitrate and ammonia are the most common forms of nitrogen in aquatic systems. Nitrate predominates in unpolluted waters. Nitrogen can be an important factor in controlling algal growth when other nutrients, such as phosphate, are abundant. Ammonia is excreted by animals and produced during decomposition of plants and animals, thus returning nitrogen to the aquatic system [1, 2]. Ammonia is also one of the most important pollutants because it is relatively common but can be toxic, causing lower reproduction and growth, or death. The neutral, unionized form (NH3) is highly toxic to fish and other aquatic life [3, 4].

There are many ways to detect the quality of water. Water quality refers to the condition of the waterbased on their characteristic such as chemical, biological and physical. Commonly measured chemical parameters are $\mathrm{pH}$ value, alkalinity, hardness, dissolved oxygen (DO), chemical oxygen demand (COD) and biochemical oxygen demand (BOD) also called as biological oxygen demand. Biological parameters are also an important factor especially for the quality of drinking water because it will give an effect on human health. The biological characteristic affecting the quality of drinking water includes protozoa, algae, virus, and bacteria. Physical aspects are also important in determining the water quality whether it is polluted or not. The parameters/characteristic are color, turbidity, taste and odor, temperature, foam, conductivity and total dissolved solids (TDS) [5, 6]. 
There are a lot of methods/devices that have been used to detect the quality of water. For chemicals, the device such as Waspmote Smart Water Sensor [7, 8] is used to monitor the water quality such as DO and $\mathrm{pH}$ value. It also can be used to detect physical characteristics such as temperature and conductivity. Spectrophotometer [9-12] is used for reagent detection of a physical parameter which is light. Another method is called the chromaticity. In order to measure the chromaticity of water and the content of dissolved matter more accurately, effectively, and cheaply, a chromaticity measurement system based on the image method was proposed and applied. The measurement system used the designed acquisition device and image processing software to obtain the Red-Green-Blue (RGB) values of the image and converted the color image from RGB color space to Hue-Saturation-Intensity (HSI) space to separate the chromaticity and brightness [13-15]. However, these devices have their own limitations. First, most of the devices need specific reagents for specific detection. Second, the devices are not portable and some of the devices have to be placed properly. Last, there are interferences on the device such as blockage and bubbles.

Realizing these limitations, researchers have proposed several microfluidic methods, i.e. paperbased and PDMS-based, to detect ammonia in freshwater. A portable 3D microfluidic paper-based analytical device (mPAD) for the determination of total ammonia (i.e., ammonia thorn ammonium) in freshwaters has been developed [16-20]. It consists of two layers of paper patterned with hydrophilic circular zones, one impregnated with sodium hydroxide (sample zone) and another (detection zone) with an acid-base indicator (nitrazine yellow (NY) or bromothymol blue (BTB)), separated by an m-distillation chamber. Another work proposed a novel method to detect ammonia by using the ninhydrin - a poly (dimethylsiloxane) (PDMS) composite [21]. The polymer composite film is prepared by integrating ninhydrin into the PDMS polymer matrix. Further, an optical lab-on-a-chip device is developed by integrating the ninhydrin-polymer composite into a microfluidic device for the detection of ammonia. The chemisorption of ammonia onto the composite resulted in the change in its optical absorption property. The proposed device has an integrated light-emitting diode and photoresistor chemicals measure the change in absorption and hence the detection and quantification of ammonia are performed [22-25]. Nevertheless, the existing microfluidic devices, although, functioning well, faces several limitations that limit practical usage, i.e. complicated fabrication, qualitative data, additional off-line data processing, effects of environmental conditions, e.g. sunlight. This paper presents the design of a capacitance-based microfluidic device that has potentials in several aspects, i.e. simple fabrication, quantitative data and real-time data processing.

\section{RESEARCH METHOD}

The focus is to design the microfluidic device based on the capacitance measurement and to simulate using finite element analysis (FEA). To make the simulation, there are two important things in a microfluidic device which are water samples and electrodes. The capacitance of a capacitor is the electrical property of a capacitor and is measured from its ability to store an electrical charge onto its two plates. A capacitor has the capacitance of one farad when a charge of one Coulomb is stored on the plates by a voltage of one volt. Capacitance is always in positive value. The relationship of capacitance is

$$
C=\frac{Q}{\Delta V}
$$

where,

$C: \quad$ Capacitance $(\mathrm{F}$, Farad)

$Q: \quad$ Charge (C, Coulomb)

$\Delta V: \quad$ Potential difference $(\mathrm{V}$, volt $)$

For this work, a method that is used is the capacitance of a parallel plate capacitor as shown in Figure 1. The capacitance of a parallel plate is proportional to the area, $A$ in metres ${ }^{2}$ of the smallest of two plates and inversely proportional to distance or separation, $d$ given in meters between two conductive plates. The equation is given below

$$
C=\frac{\varepsilon_{0} \varepsilon_{r} A}{\mathrm{~d}}
$$

The water samples used in this work are normal river water and contaminated river water with ammonia in it. A water sample is passed through between the electrodes. The electrodes which are connected to the electrical circuit measure the value of capacitance (refer to the (2)). 


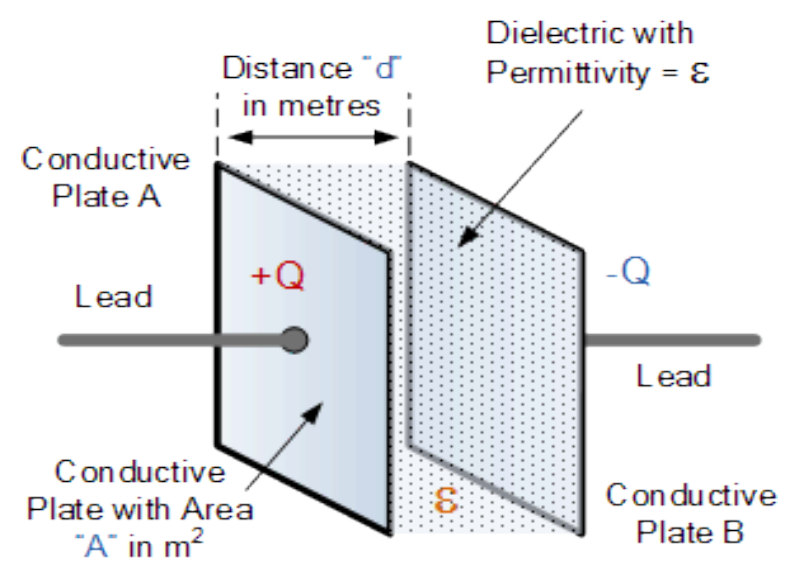

Figure 1. Schematic of the parallel plate capacitor

Where,

$\varepsilon_{0}$ : Permittivity of free space, $8.84 \times 10^{-12} \frac{F}{m}$

$\varepsilon_{r}$ : Relative permittivity of dielectric between two plates

$A$ : Area of plate $\left(\mathrm{m}^{2}\right)$

$d$ : Distance between two plates $(m)$

\section{RESULTS AND ANALYSIS}

The microfluidic device is simulated by using finite element analysis (FEA) (COMSOL Multiphysics). Several investigations have been conducted from the simulation, i.e. the size of the electrode, the difference in water flow gap, the distance between the electrodes, speed of the water and the capacitance of the water. The microfluidic device was designed according to the prototype. The dimension is $5 \mathrm{~cm}$ (length) x $2 \mathrm{~cm}$ (width) x $1 \mathrm{~cm}$ (height). The material used for the body of the device is PDMS. Next, the dimensions of the water flow inlet, channel, and outlet were designed. Finally, the design of the electrodes was performed. The dielectric of the contaminated water is 16.5 and the normal water is 80 . Figure 2 shows the commercial microneedle which is used in the design for the electrode [26]. In this simulation, the tip of the electrode was chosen as a flat surface. The material used for the electrode is tungsten. There are two sizes, $125 \mu \mathrm{m}$, and $250 \mu \mathrm{m}$. Figure 3(a) shows the modeled device in 3D while Figure 3(b) shows the device in $3 \mathrm{D} y z$-plane.

There are three different sizes of water flow gap which are $10 \mathrm{~mm}, 1 \mathrm{~mm}$ and $0.1 \mathrm{~mm}$. The electrode size that was used in the simulation $125 \mu \mathrm{m}$ and $250 \mu \mathrm{m}$. There are three distances of the electrode gap which are $1 \mathrm{~mm}, 0.5 \mathrm{~mm}$, and $0.25 \mathrm{~mm}$. The results of the simulation are the effect of the velocity of the water flow in the device and the capacitance of each of the samples. Results from the simulation are tabulated in Tables 1-6. The water flow gap at $10 \mathrm{~mm}$ is the largest size used in the simulation. This is to investigate the effect of the velocity of the water on the size of the electrode and the gap between the electrodes. Compare with Table 1 and Table 2, the velocity at the input is the same at $1 \mathrm{~m} / \mathrm{s}, 5 \mathrm{~m} / \mathrm{s}$, and $10 \mathrm{~m} / \mathrm{s}$. The electrode gap used also the same. Based on the result most of the output velocity of the water for each electrode gap is the same but the velocity of the water between the electrode gap is different. This is because the area of the gap between the electrode is smaller. The capacitance is different due to the electrode sizes and the gap between the electrodes. For the water flow at $1 \mathrm{~mm}$, the input velocity is the same and the output velocity is slightly the same as shown in Figure 3 and Figure 4. However, the velocity of water in the electrode gap is different. Again, this is because of the small area between the electrode gaps. The capacitance is also different due to the electrode sizes and the gap between the electrodes. For the water flow at $0.1 \mathrm{~mm}$, there are changes that have been made due to the smaller size of the water flow. The velocity of inlet water is the same for both the size of the electrode. As the gap of the electrode is decreased, the velocity of the outlet and the electrode gap is the same. The velocity is getting higher at the electrode gap and the outlet. This is because the area of the electrode gap is very small and the is pressure is high, so it gives an effect on the velocity of the outlet. 
Less than 1 micron tip dia.

$(125 \mu \mathrm{m} \times 50 \mathrm{~mm})$

Approx. 3 micron tip dia.

$(125 \mu \mathrm{m} \times 50 \mathrm{~mm})$

Less than 1 micron tip dia.

$(250 \mu \mathrm{m} \times 50 \mathrm{~mm})$

Approx. 5 micron tip dia.

$(250 \mu \mathrm{m} \times 50 \mathrm{~mm})$

Figure 2. Image of the microneedle

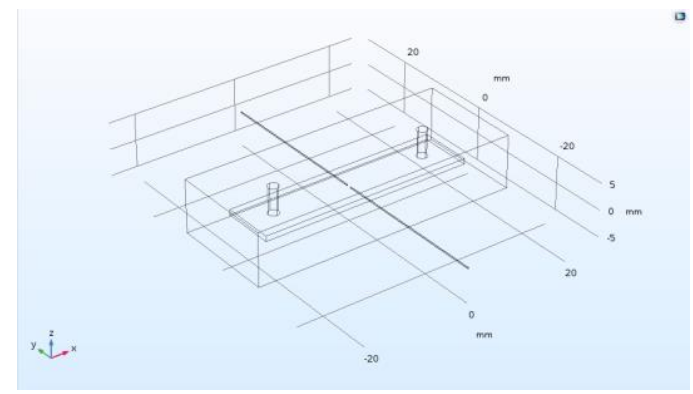

(a)

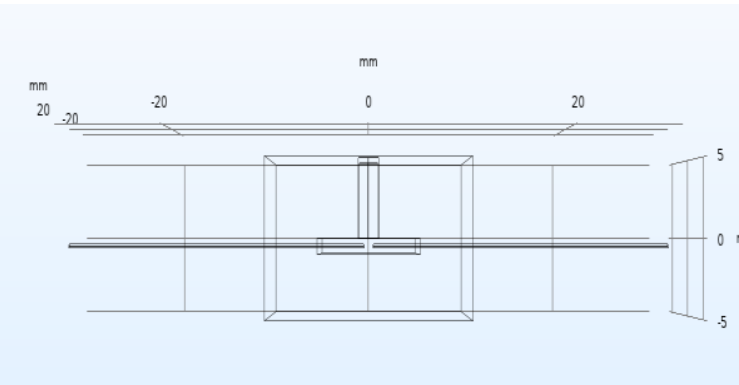

(b)

Figure 3. (a) Drawing of the 3D microfluidic model, (b) Drawing of the 3D yz-plane of microfluidic model

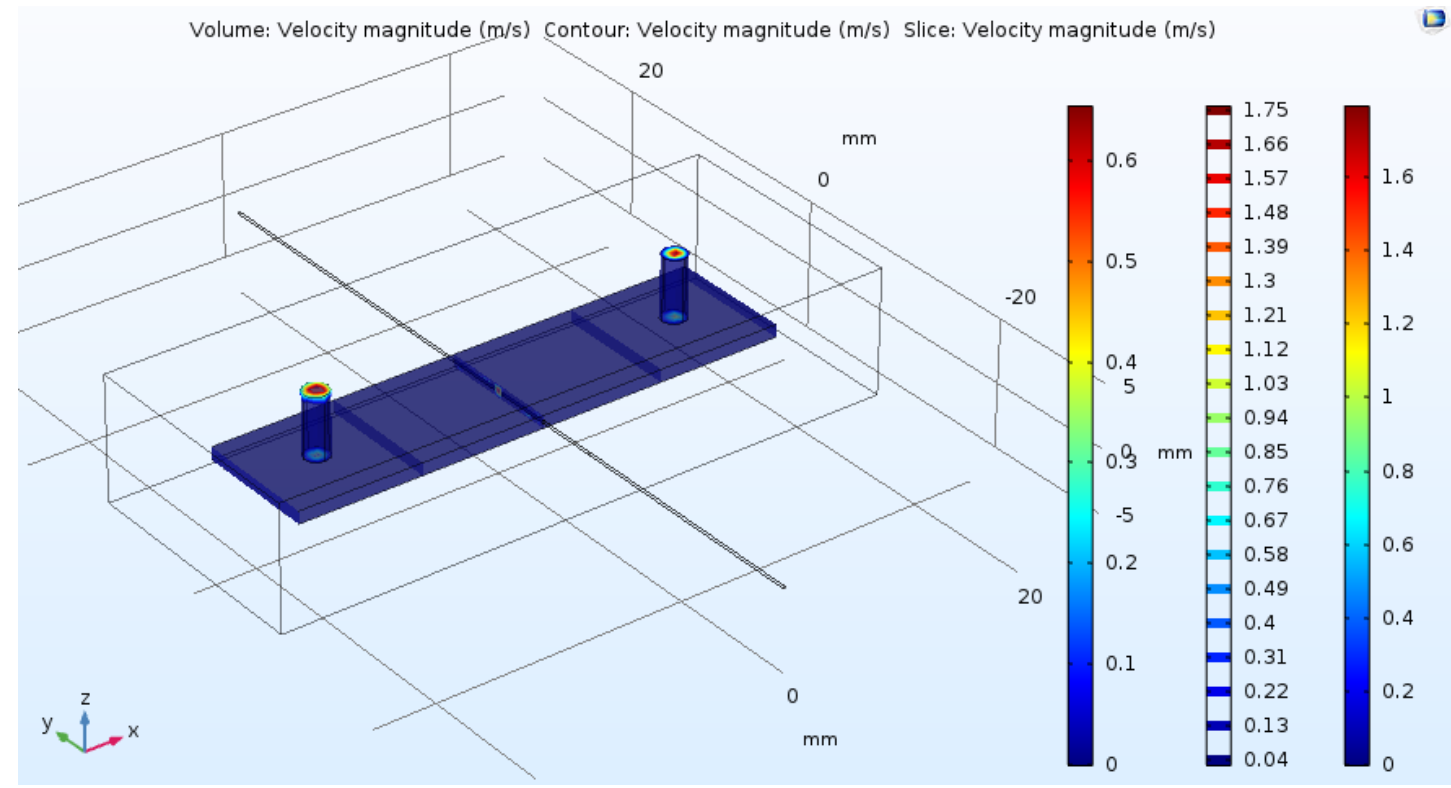

Figure 4. Simulation result 
Table 1. The electrode size at $250 \mu \mathrm{m}$ and water flow gap $10 \mathrm{~mm}$

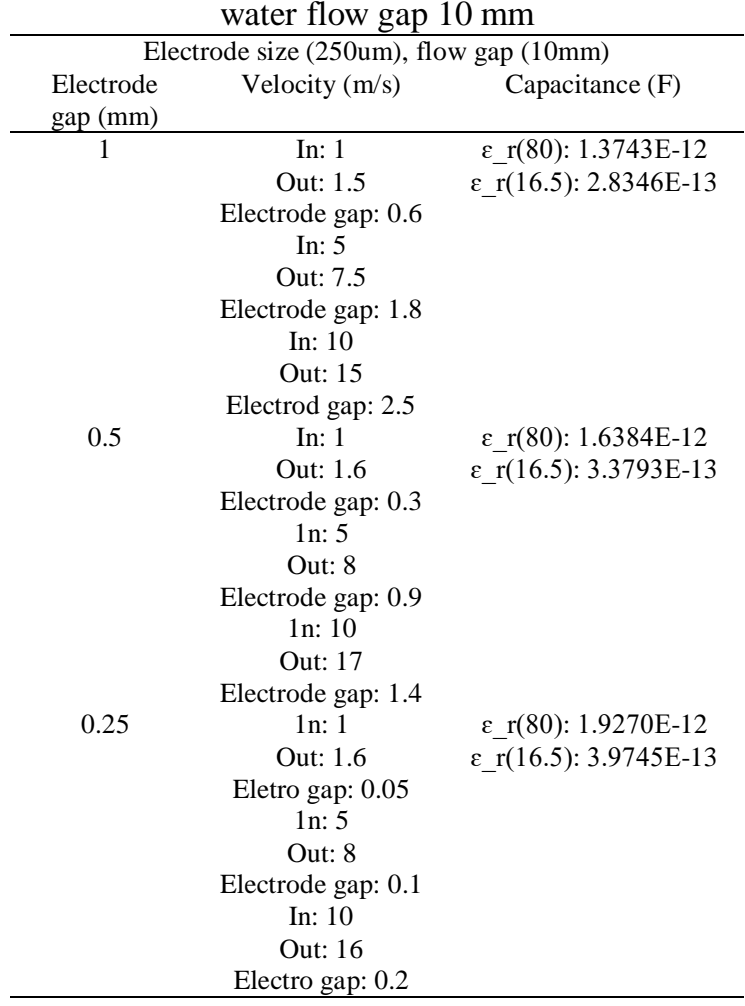

Table 3. The electrode size at $250 \mu \mathrm{m}$ and water flow gap $1 \mathrm{~mm}$



Table 2. The electrode size at $125 \mu \mathrm{m}$ and water flow gap $10 \mathrm{~mm}$

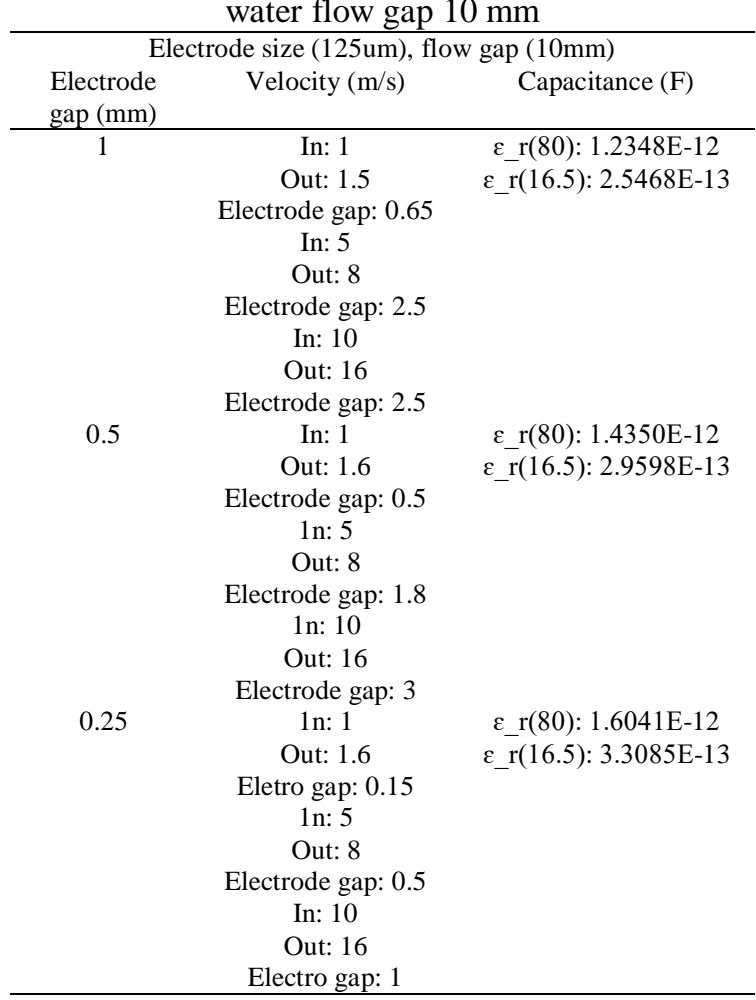

Table 4. The electrode size at $125 \mu \mathrm{m}$ and water flow gap $1 \mathrm{~mm}$

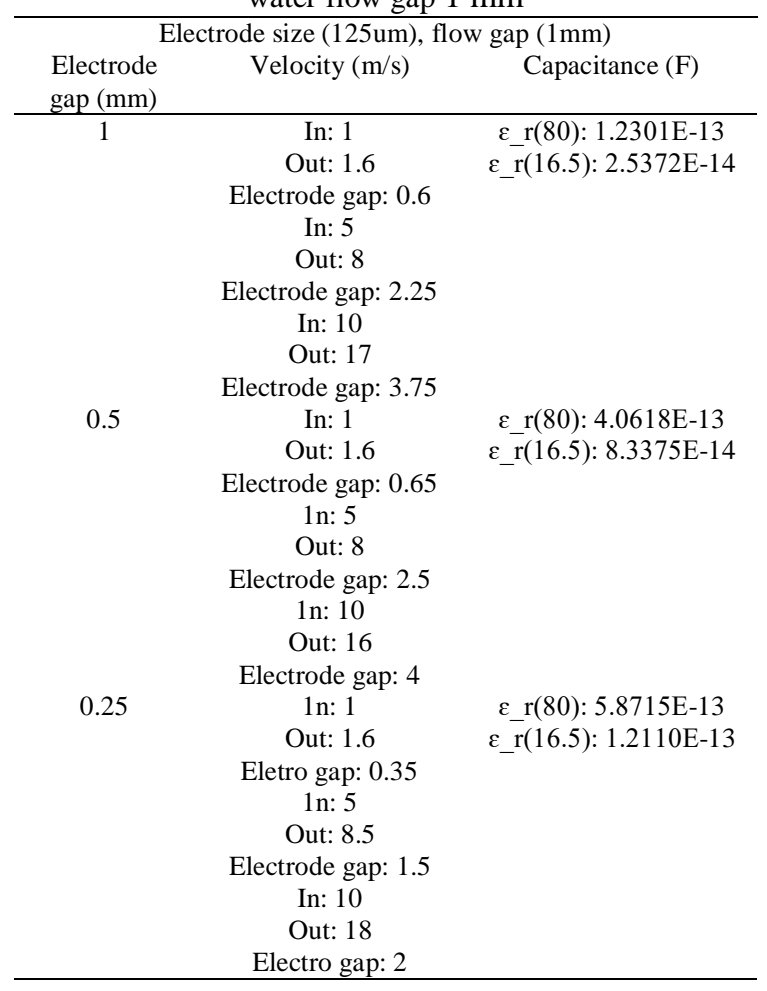


Table 5. The electrode size at $250 \mu \mathrm{m}$ and water flow gap $10 \mathrm{~mm}$

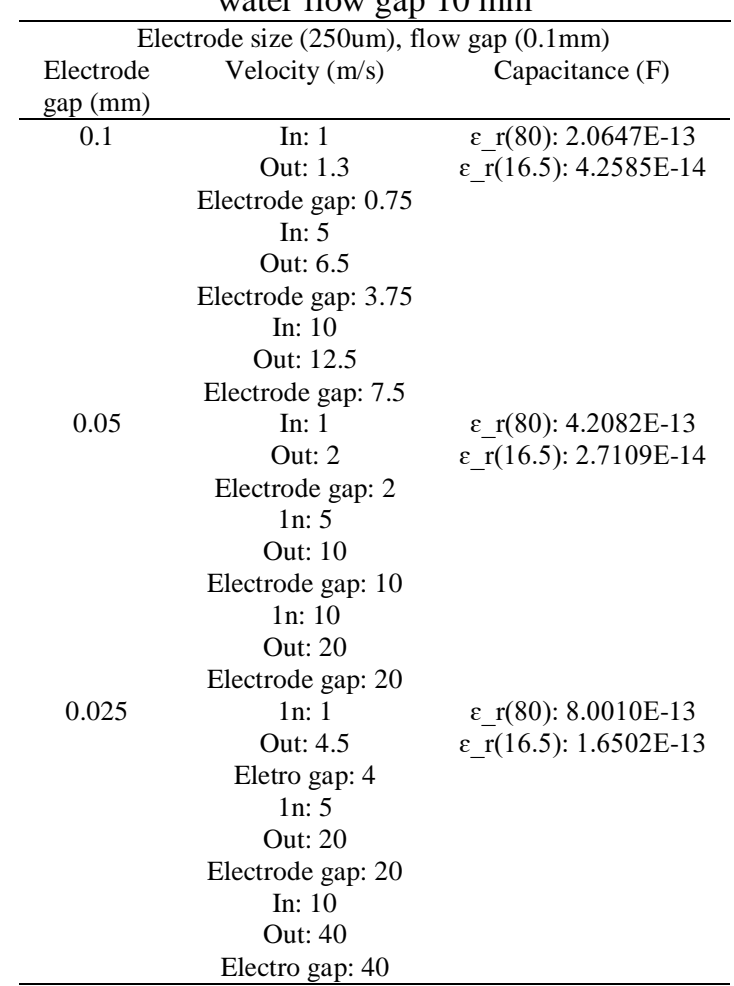

Table 6. The electrode size at $125 \mu \mathrm{m}$ and water flow gap $0.1 \mathrm{~mm}$

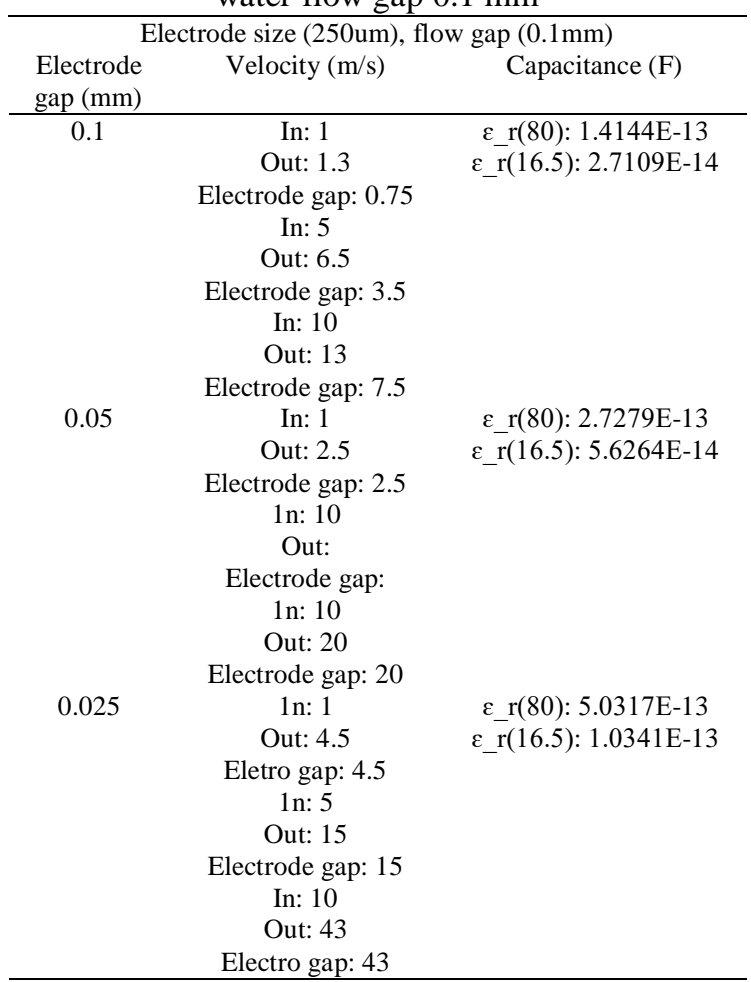

\section{CONCLUSION}

Simulation results showed that there are a lot of factors or parameters that can be tested. With parameters such as electrode size, electrode gap, flow gap, the velocity of water and capacitance that have been investigated, it can be concluded that the device can be used in many conditions. This paper describes the system in detail from the conceptual idea to the hardware implementation. The microfluidic device works by inserting the sample of water into the device to be tested. A pair of electrodes is connected to the electrical circuit and the value of the capacitance of the water sample is measured. The tested samples are normal river water and contaminated river water which have ammonia in it. The results showed that the proposed microfluidic design is capable to detect ammonia inside river water under 2 ppm concentration.

\section{ACKNOWLEDGEMENTS}

The research was supported by the Ministry of Higher Education of Malaysia and Universiti Teknologi Malaysia (Grant Nos. Q.J130000.21A2.04E82 and Q.J130000.2523.19H22); we thank them for funding this project and for their endless support.

\section{REFERENCES}

[1] M. Camara, N. R. B. Jamil, and F. B. Abdullah, "Variations of water quality in the monitoring network of a tropical river," Global Journal of Environmental Science and Management, vol. 6, no. 1, pp. 85-96, 2020.

[2] C. K. C. Ng, P. A. C. Ooi, W. L. Wong, and G. Khoo, "First development of the Malaysian River Integrity Index (MyRII) based on biological, chemical and physical multi-metrics," Journal of Environmental Management, vol. 255, 2020.

[3] M. Qi, Y. Yang, X. Zhang, X. Zhang, M. Wang, W. Zhang, et al., "Pollution reduction and operating cost analysis of municipal wastewater treatment in China and implication for future wastewater management," Journal of Cleaner Production, vol. 253, 2020.

[4] D. Qi, J. Yan, and J. Zhu, "Effect of a reduced fertilizer rate on the water quality of paddy fields and rice yields under fishpond effluent irrigation," Agricultural Water Management, vol. 231, 2020.

[5] N. H. F. Hashim, M. A. Mohd Idris, M. Abdullah, M. F. Ahmad Tajuddin, H. Jamaluddin, R. A. Trevor Gunggang, et al., "Water quality assessment of the langat river, Selangor," Malaysian Applied Biology, vol. 47, pp. 9-15, 2018. 
[6] L. Nyangon, S. Gandaseca, A. M. M. Pazi, and A. E. Tindit, "Water quality assessment of Sepetang River at Matang mangrove forest, Perak," Malaysian Forester, vol. 81, pp. 183-198, 2018.

[7] B. Siregar, K. Menen, S. Efendi, U. Andayani, and F. Fahmi, "Monitoring quality standard of waste water using wireless sensor network technology for smart environment," in 2017 International Conference on ICT for Smart Society, ICISS 2017, pp. 1-6, 2018.

[8] B. Siregar, A. B. A. Nasution, and F. Fahmi, "Integrated pollution monitoring system for smart city," in 2016 International Conference on ICT for Smart Society, ICISS 2016, pp. 49-52, 2016.

[9] J. Ma, H. Shu, B. Yang, R. H. Byrne, and D. Yuan, "Spectrophotometric determination of $\mathrm{pH}$ and carbonate ion concentrations in seawater: Choices, constraints and consequences," Analytica Chimica Acta, vol. 1081, pp. 18-31, 2019.

[10] N. Nordin, A. B. Jawan, V. B. Sumin, M. B. Mokhtar, and G. C. Ta, "Assessment of Human Health Risk in Groundwater at Rural and Agriculture Areas in Sabah, Malaysia," in 12th Seminar on Science and Technology 2018, vol. 1358, no. 1, p. 012072, 2019.

[11] M. Krishnakartik, S. Satyaveni, and P. V. S. Machiraju, "An investigative study on subsurface water chemistry near agricultural and aquaculture areas," International Journal of Environmental Analytical Chemistry, 2020.

[12] W. T. Bolleter, C. J. Bushman, and P. W. Tidwell, "Spectrophotometric Determination of Ammonia as Indophenol," Analytical Chemistry, vol. 33, pp. 592-594, 1961.

[13] P. Cao, Y. Zhu, W. Zhao, S. Liu, and H. Gao, "Chromaticity measurement based on the image method and its application in water quality detection," Water (Switzerland), vol. 11, 2019.

[14] J. Breneman, H. Blasinski, and J. Farrell, "The color of water: Using underwater photography to estimatewater quality," in Digital Photography X, San Francisco, CA, 2014.

[15] X. Zhao, W. Shen, J. Huang, Q. Yu, and J. Lou, "Standard for water color determination based on three-wavelength luminous transmittance," Chinese Journal of Environmental Engineering, vol. 7, pp. 4766-4772, 2013.

[16] S. A. Jaywant and K. Mahmood Arif, "A comprehensive review of micro fluidic water quality monitoring sensors," Sensors (Switzerland), vol. 19, 2019.

[17] A. Jang, Z. Zou, K. K. Lee, C. H. Ahn, and P. L. Bishop, "State-of-the-art lab chip sensors for environmental water monitoring," Measurement Science and Technology, vol. 22, 2011.

[18] J. J. Peters, M. I. G. S. Almeida, L. O'Connor Šraj, I. D. McKelvie, and S. D. Kolev, "Development of a microdistillation microfluidic paper-based analytical device as a screening tool for total ammonia monitoring in freshwaters," Analytica Chimica Acta, vol. 1079, pp. 120-128, 2019.

[19] N. A. Meredith, C. Quinn, D. M. Cate, T. H. Reilly, J. Volckens, and C. S. Henry, "Paper-based analytical devices for environmental analysis," Analyst, vol. 141, pp. 1874-1887, 2016.

[20] J. L. Delaney, C. F. Hogan, J. Tian, and W. Shen, "Electrogenerated chemiluminescence detection in paper-based microfluidic sensors," Analytical Chemistry, vol. 83, pp. 1300-1306, 2011.

[21] J. Ozhikandathil, S. Badilescu, and M. Packirisamy, "Polymer composite optically integrated lab on chip for the detection of ammonia," Journal of the Electrochemical Society, vol. 165, pp. B3078-B3083, 2018.

[22] E. Fornells, E. Murray, S. Waheed, A. Morrin, D. Diamond, B. Paull, et al., "Integrated 3D printed heaters for microfluidic applications: Ammonium analysis within environmental water," Analytica Chimica Acta, vol. 1098, pp. 94-101, 2020.

[23] J. Gouyon, F. d'Orlyé, S. Griveau, F. Bedioui, and A. Varenne, "Characterization of home-made graphite/PDMS microband electrodes for amperometric detection in an original reusable glass-NOA®-PDMS electrophoretic microdevice," Electrochimica Acta, vol. 329, 2020.

[24] H. Zhou and Z. Yang, "The Reversible Ammonium Detection Based on the Coupled Microfluidic Chipand the Investigation of the Impact Factors," Guang Pu Xue Yu Guang Pu Fen Xi/Spectroscopy and Spectral Analysis, vol. 39, pp. 3749-3754, 2019.

[25] J. Gallardo-Gonzalez, A. Baraket, S. Boudjaoui, T. Metzner, F. Hauser, T. Rößler, et al., "A fully integrated passi ve microfluidic Lab-on-a-Chip for real-time electrochemical detection of ammonium: Sewage applications," Science of the Total Environment, vol. 653, pp. 1223-1230, 2019.

[26] MicroProbes. (2015). Tungsten Micro-Needles. Available: http://microprobes.com/index.php/products/otherproducts/micro- 